Samples of the cable and strands incorporated into the cable are sent to BNL. Representarive samples of uncabled strands are tested for $I_{c}$ at various fields. The results of these strand tests are used in the determination of cabling degradarion and can also exhibit a reasonable estimation of the performance of the cable 2 . Calculation of the cable degradation was done somewhat differently in this report due to the retrospective availability of wire data Cable degradation is discussed at length in a later section of this paper. Because production scale teating allows only for a few measurements of the cable specimen, the full Le vs. B curve of the cable is fitted using the slope of the wire curve (averaged from alf wire samples tested). Previous experiments have showed that the two slopes agree sell and the resulting accuracy is about $\pm 150 \mathrm{~A} .{ }^{2}$ All critical current measurements are done at a temperature of approximately $4.35 \mathrm{~K}$ because of the incrensed pressure due to the forced glow cowling throughout the test magnet. All reported values of the $\mathrm{I}_{c}$ are calculated for the reference temperature of $4.22 \mathrm{~K}$

Resistance measurements are made on the cable at room temperature (R295) and at 10K (R10), and the Residual Resistance Ratio calculated (RRR $=\mathbf{R 2 9 5} / \mathbf{R} 10)$. The copper to superconductor ratio is deternined from these resistance values, and in tum the $\mathrm{Cu} / \mathrm{sc}$ is used in calculating the critical current density $\left(J_{C}\right)$ of the cable.

The mechanical testing of cable is just as important as the electrical measurements to ensure a reliable magnet. The dimensional control of the cable is monitored by the Cable Measuring Machine. The CMM is an in-line device that periodically (currently $10 \mathrm{ft}$. intervals) measures the cable width, mid-thickness, and keystone angle as the cable is being produced. A series of tests and spot-checks are performed befure each cable run. These tests examine the residual twist of the cable, as well as the surface quality, lay pitch, lay direction, and bere filament integrity. 3.4

\section{SSC WIRE}

Supereonducting wire is the single most importunt component of the SSC cable fabrication process, therefore a short outline of the wire propecties and parameters are includod.

\section{SSC Outer Wire (Trible 1a)}

\begin{tabular}{|c|c|c|c|c|}
\hline No & Total Len & Length $>$ & $L \geq$ & $\frac{\text { Norm 1e (3 }}{29285}$ \\
\hline $2071-1$ & 264,889 & 227,419 & 85.90 & 292.85 \\
\hline $2071-2$ & 231,260 & 150,273 & 65.00 & 294.65 \\
\hline $2126-1$ & 260,767 & 230,094 & 88.20 & 296.15 \\
\hline $2 \sqrt{28-2}$ & 183.216 & 183.216 & 100.00 & 29881 \\
\hline $2128-3$ & 340,232 & 331,417 & 97.40 & 30268 \\
\hline 80359 & 392120 & $3,32,120$ & 84.70 & 310.00 \\
\hline BO0397 & 388,381 & 337,882 & 87.00 & 313.99 \\
\hline $2301-1$ & 394131 & $3,60,285$ & 91.90 & 281.07 \\
\hline
\end{tabular}

SSC Inner Wire (Table 1b)

\begin{tabular}{|c|c|c|c|c|c|}
\hline BHllet : & Total Length & Length > IOK & $\% L>10 K$ & Norm le (7I) & Type \\
\hline $2121-1$ & 216,231 & $168.60 !$ & 78.00 & 334.37 & 1.5 \\
\hline $\mathrm{B} 030^{\circ}$ & 237,115 & 155,934 & 65.70 & 365.90 & 1.5 \\
\hline B0310 & $2 \sqrt[3]{2,753}$ & 165,464 & 71.00 & 353.37 & 1.5 \\
\hline $23000-1$ & 183,652 & 138,414 & 75.40 & 35351 & 5 \\
\hline $2346-1$ & $2 6 \longdiv { 2 1 8 }$ & 240,046 & 91.90 & 364.28 & .3 \\
\hline $2346-2$ & 264.232 & 224,173 & 84.80 & 366.07 & 1.3 \\
\hline $2346-3$ & $1 6 \longdiv { , 6 9 4 }$ & 35,568 & 22.10 & 361.41 & 1.3 \\
\hline
\end{tabular}

Tables la and $1 b$ list the data used in constructing Figures $1 \mathrm{a}$ and $1 \mathrm{~b}$ and Figures $2 \mathrm{a}$ and $2 \mathrm{~b}$. Total length is the length of wire shipped for cabling after meeting SSC 
specifirationa. The $I_{c}$ reported here for these billets is the sum of the critical currents of cac. ce normä̈zed with its length. This means that a long piece will have a larger contribution to the total normalized billet $I_{c}$ than a short piece. Mathematically, the normalized $\mathrm{L}_{e}$ for a billet is:

$$
\begin{aligned}
& I_{\cos }=\Sigma I_{\infty x} l_{x} / L \quad \text { where } \quad L=\text { low length } \\
& \mathrm{I}_{\mathrm{a}} \text { = piece critical current } \\
& l_{2}=\text { piece length } \\
& \text { Len = normalized billet crivical current } \\
& \text { ssc Outer ic } \\
& \text { (normallzed with length) }
\end{aligned}
$$

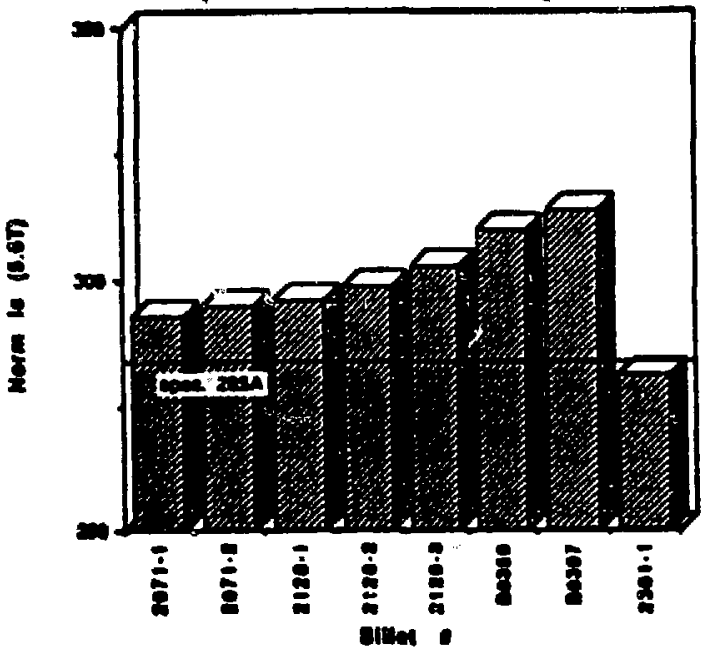

Figure la

Figure 1a shows the illustration of how well each SSC outer billet has performed against the SSC critical current specification. In all cases except one this requirement was comfortubly met. Although billet 2301-1 fell slightly below the $L_{c}$ specification for SSC wire, a low degradation during cabling allosed this material to produce ecoepenble cable.

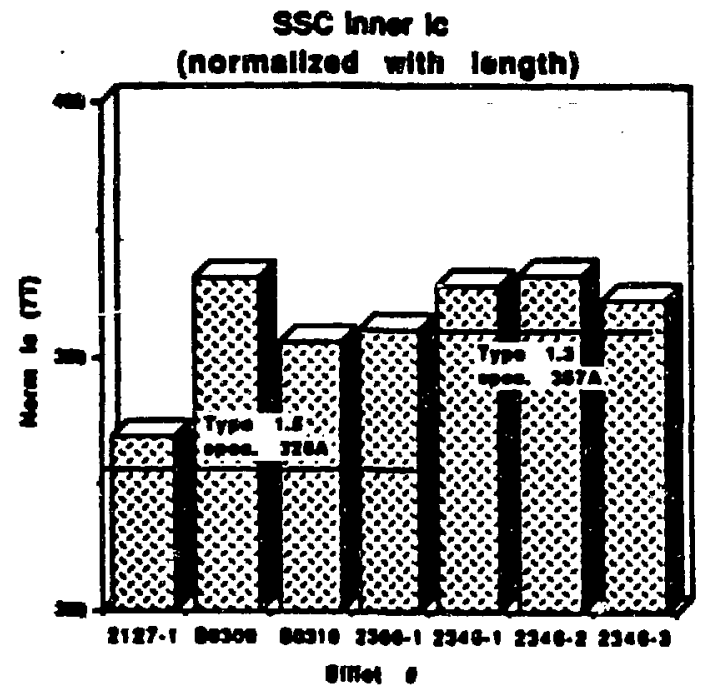

Figure 1b

Figure 1b is the equivalent of 1a for SSC inner billet data. All seven billets represented here meet the SSC specification. However, the four with a Cu/SC ratio of 1.5 exceed the minimum specified $L_{c}$ by a larger margin. 


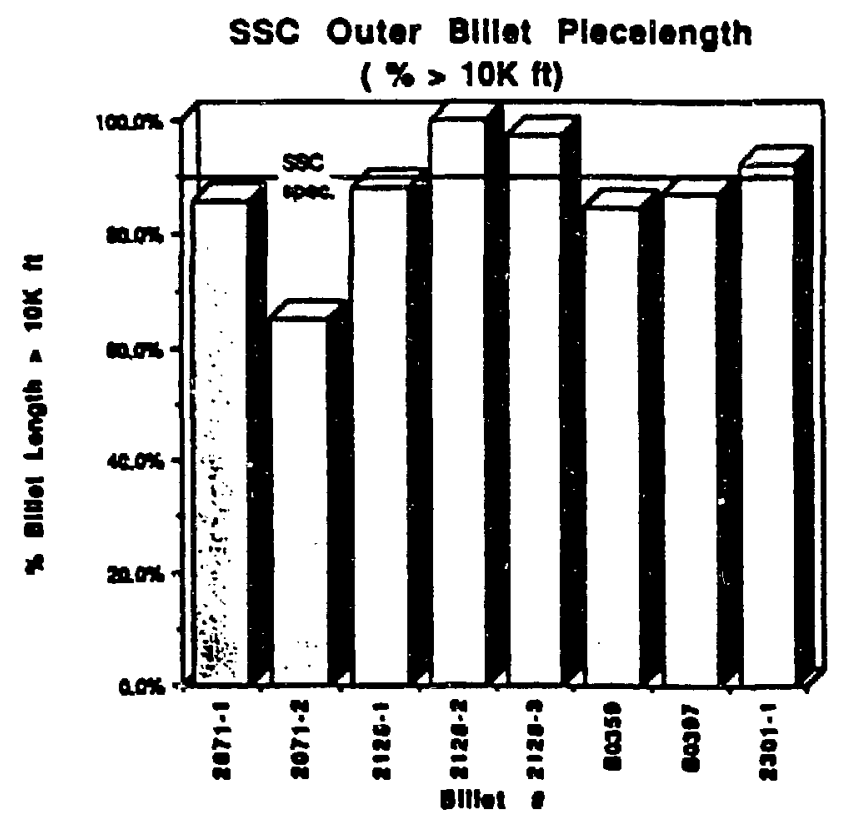

Figure $2 a$

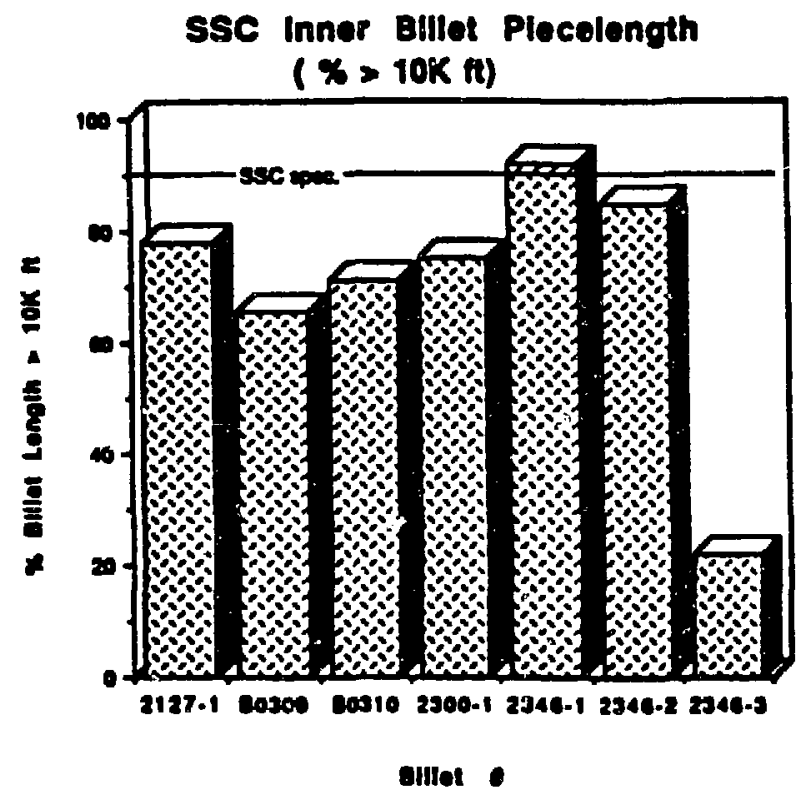

Figure 2b 
Figures $2 \mathrm{a}$ and $\mathbf{2 b}$ show the piece length performance of acceptable strand from each billet it is obvious that very few billets actualiy $\mathrm{u}$. ihe proposid SSC requirement of 90\% > 10,000 feet. As more experience is gained in maxing SSC conductor, it is expecred that this piece length problem will be rectified. Piece length is only one facet in to piture however. To get a better idea of billet performance, the overall yield (rotal length) must also be considered. For example, billet $2128-2$ has $100 \%$ of its acceptable lengths greater than 10,000 feet Yet the sum of all acceptable lengths only reaches 183,216 feet. Depending upon the initial size of the assembled multiflament billet, this yield could be as low as $50 \%$. Further information must be acquired from the wire manufacturer in order to clarify this point.

\section{SSC PRE-PRODUCTION CABLE}

Pre-Production cable is considered to be cable made with the "main line" SSC conductor. This is the wire fabricated to meet the existing SSC wire specification document ${ }^{3}$ Wire designed to address a specific issue for research purposes is considered RED and is briefly discussed in a later section.

SSC Outer Pre-Production Cable (Table 2a)

\begin{tabular}{|c|c|c|c|c|c|}
\hline Cable & Length & $I_{e}$ (5T) & $I_{\text {s }}$ (5.6T) & Deg. & Material Inc \\
\hline SSC22-00004 & 13,075 & 9516 & 8338 & $7.10 \%$ & $2128-1,2.3$ \\
\hline SSC22-00005 & 13,623 & 9800 & 8608 & $3.40 \%$ & 2071,2128 \\
\hline SSC22-00006 & 11,000 & 9661 & 8488 & $4.70 \%$ & 2071,2128 \\
\hline SSC22-00007 & 4,400 & 9247 & 8138 & $7.60 \%$ & 2011 \\
\hline SSC22-00008 & 11,091 & 9216 & 8135 & $3.50 \%$ & $2301-1$ \\
\hline SSC23-00001 & 11,800 & NA & NA & NA & B0359 \\
\hline SSC-0-1-00002 & 11,267 & NA & NA & NA & B0397 \\
\hline Total Length $=$ & 76,256 & & & & \\
\hline
\end{tabular}

Table 2a shows the SSC outer type pre-production cable fabricated in 1989 and 1990 to date. The minimum $\mathrm{L}_{e}$ at 5.6T is specified to be 7860A. The column labeled Material Ine" shows the material incorporated into each cabling run, thus the cable performance can be referenced back to the appropriate billet and comparisons can be made.

SSC Inner Pre-Production Cable (Table 2b)

\begin{tabular}{|c|c|c|c|c|c|}
\hline Cable & Length & $I_{c}$ (TI) & Des. & Inc Material & Type \\
\hline SSC12-00001 & 5,336 & 7465 & $2.90 \%$ & $2127-1$ & 1.5 \\
\hline SSC12-00005 & 3,613 & 7407 & $3.70 \%$ & $2127-1$ & 1.5 \\
\hline SSC12-00007 & 7,100 & 7822 & $4.30 \%$ & $2300-1$ & 1.5 \\
\hline SSC-I-S-00008 & 7,894 & 8094 & $3.30 \%$ & $2346-1,2,3$ & 1.3 \\
\hline SSC-I-S-00009 & 8,935 & NA & NA & $2346-1,2,3$ & 1.3 \\
\hline SSC-I-S-00010 & 10,800 & 8368 & $0.00 \%$ & $2346-1,2,3$ & 1.3 \\
\hline SSC-13-00003 & 8,572 & 7840 & $3.50 \%$ & B0310 & 1.5 \\
\hline SSC-I-I-00003 & NA & NA & NA & B0309 & 1.5 \\
\hline Total Length $=$ & 52,250 & & & & \\
\hline
\end{tabular}

Similarly, Table $2 \mathrm{~b}$ lists the SSC inner type pre-production cable for the same period. The 
minimum $\mathrm{L}_{\mathrm{c}}$ at $T \mathrm{~T}$ is $723 \mathrm{lA}$ for type 1.5 cable, and $7860 \mathrm{~A}$ for type $1.3 \mathrm{c}^{-1} \cdot 3$ (Typi $1 \mathrm{~s}$ designates the use of wire with a 1.5:1 copper to superconductor ratio, all :"kewise type 1.3 uses $1.3: 1 \mathrm{Cu} / \mathrm{sc}$ strand). Also included in Tables $2 \mathrm{a}$ and $2 \mathrm{~b}$ is the tosat footage of production outer $(76,250)$ and inner $(52,250)$ cable made during this period.

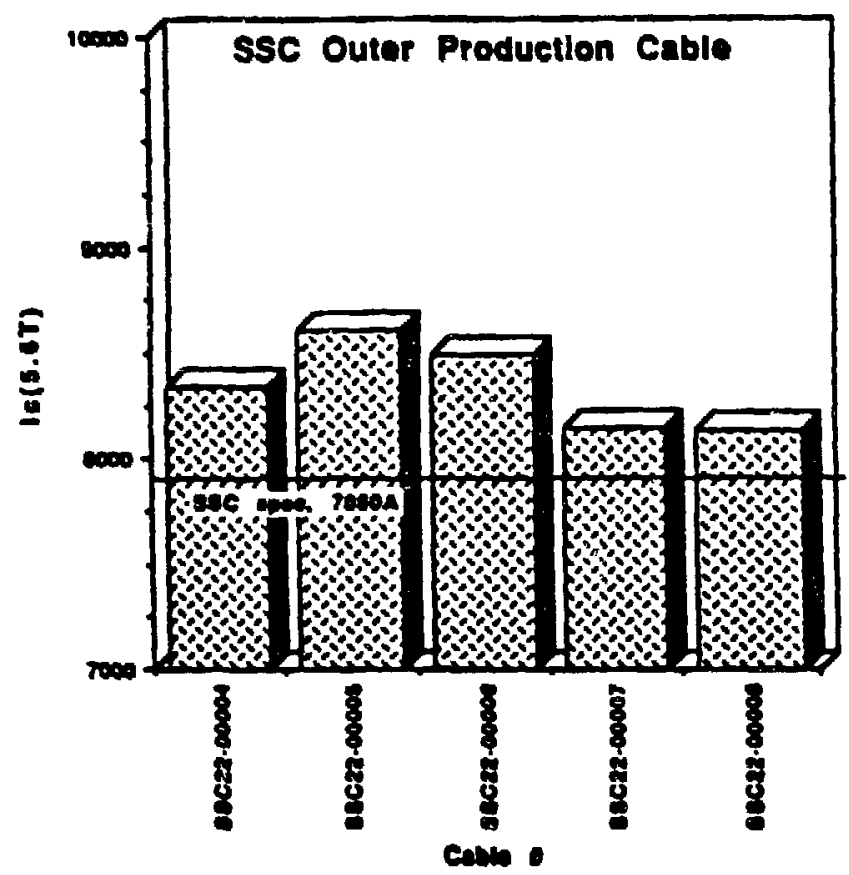

Figure 3.

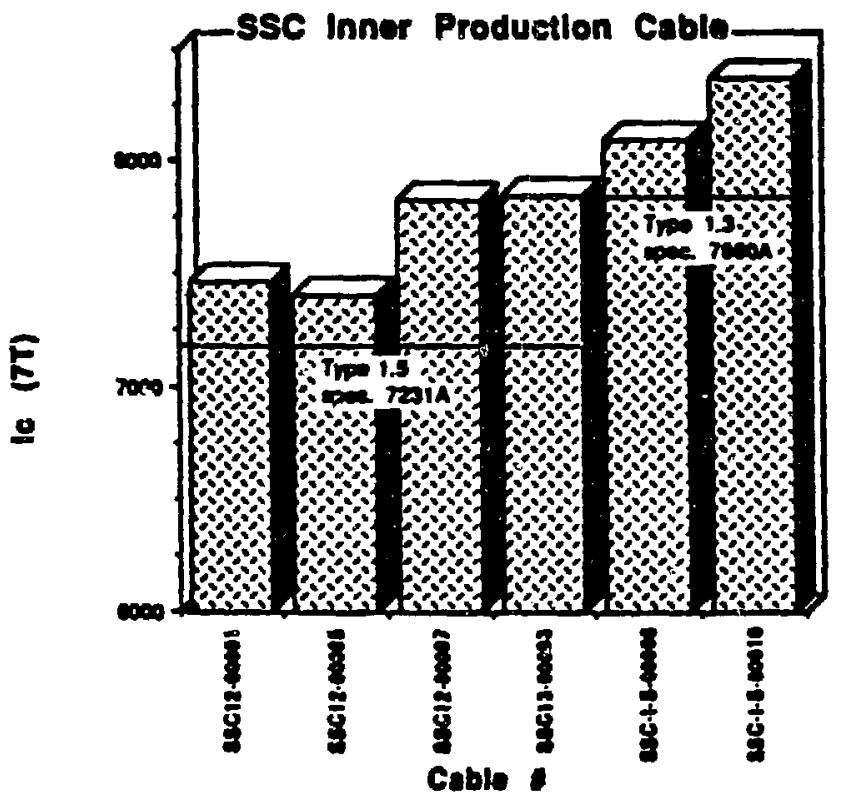

Figure $3 b$

Figures $3 a$ and $3 b$ show a bar chan plot of the $L_{c}$ for the cuter and inner cable that have been measured wo date. 


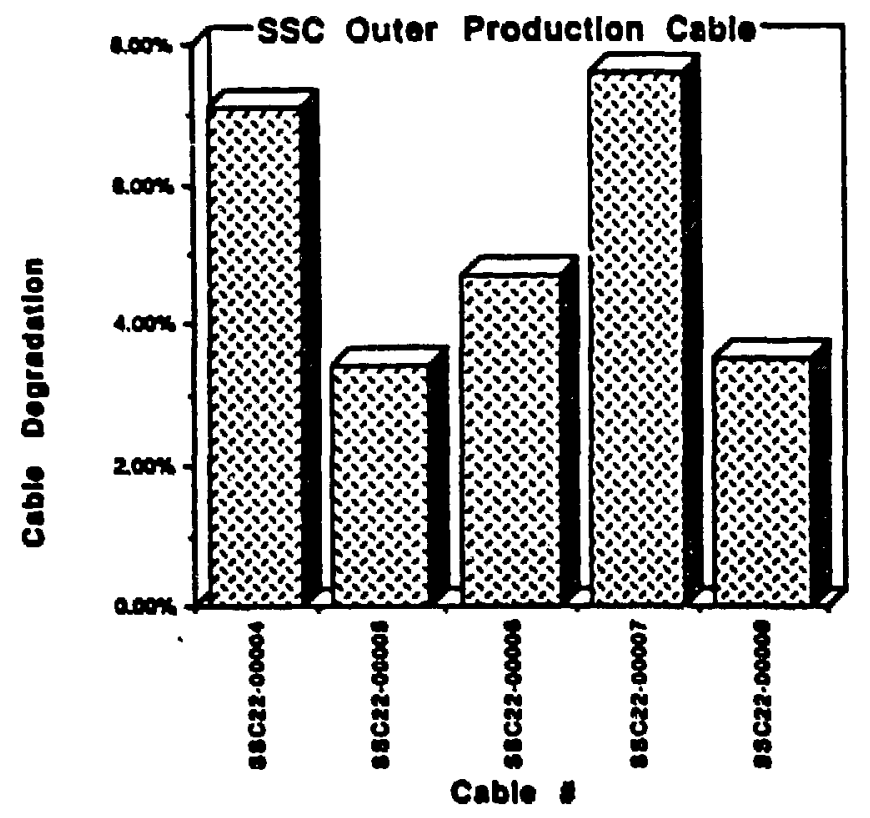

Figure 4 a

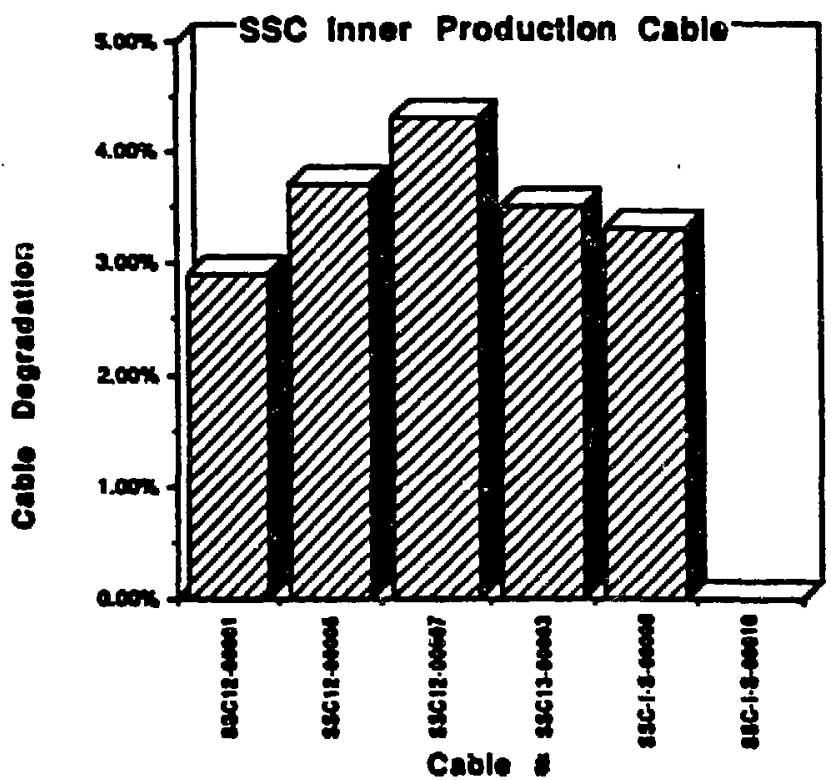

Figure 4b

The degradation values listed in Tables $2 a$ and $2 b$, and illustrated in Figures $4 a$ and 4b, show the approximate decrease in current carrying properties of the cabled strinds afier experiencing the deformation introduced in the cabling operation. These values are computed by using the nomalized I numbers of the material involved in the comesponding cabling run. This is multiplied by the number of strands in the cable ( 23 for inner, 30 for outer) and divided into the reported $\mathrm{L}_{c}$ of the cable. The result of this quotient is subtracted from 1.0 giving the percentage of degradation induced by the cabling process. Depending upon the method used in calculating degradation, values can vary between sources. Because of the limited availability of piece length and $\mathrm{L}_{c}$ data for billets, historically the before cabling' $Z_{c}$ used in figuring degradation has been an approximation based on a few strand rests. Using the normalized $\mathrm{I}_{c}$ as is done here takes into consideration each strand used in the cable. 
Cable degradation can be influenced by numerous factors, some of which can be control: $i$ the cabling operation. Certainly a properly aligned and properly set-up machine whi help to lower degradation. This seems to be the case for cable SSC-I-S-00010 where the degradation is small enough to be lost in the error factors of the measurements. Compaction is the largest parameter affecting cabling degradation. The higher the compaction, the higher the degadation. Therefore, it is desirable to make cable th the higher end of the midthickness specification limit as long as this limit is nct exceeded. This is demonstuted by a simple comparison between the degradation in cables SSC22-0000s and SSC22-00007. SSC22-00007 experienced a consistently higher compaction throughout the nun which explains the higher degradation measured.

Sources of cabling degradation can also be a result of traits inherent in the strand itself. The shape and proximity of the filament arry in relation to the outside diameter of the wire has been known to contribute to the amount of cable degradation. Higher degradation has been observed in strand with an insufficient amount of copper surrounding the matrix. This deficiency of copper cladding fails to protect the filaments and absorb the deformation introduced during cabling. In Figure 5 we compare the degradation in cables $12-00007,13-00003$, and 12-00001, and we can see a relative fit to the factors described

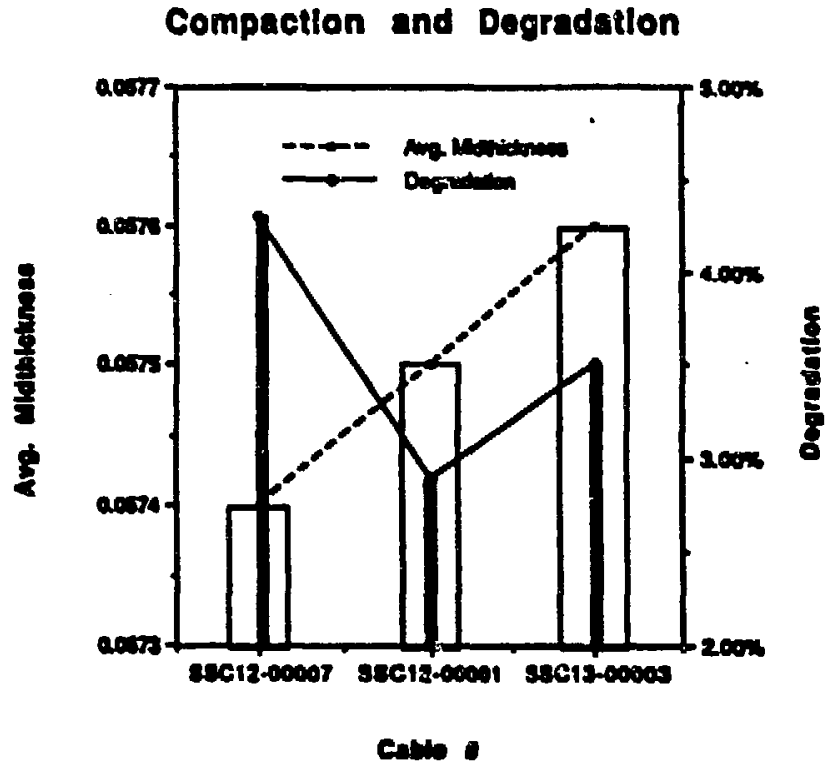

Figure 5

above. The high degradation in 12-00007 can be auributed to the higher compaction (lower average midthickness). However, if we compare 13-00003 and 12-00001, we see a reverse result Although 13-00003 has a lower compaction, the degradation is higher. This may be attributed to the fact that strand used in 13-00003 has a cross section that is undesirable in terms of cabling degradation. The overall filamentary array has a hexagonal pattern in which the poines of the hex come relatively close to the outside diameter of the strand. The problems associated with such a cross section are mentioned above.

Dimensional measurements and staaistics of the cable are monitored by the Cable Measuring Machine (CMM) as the cable is being produced. Usir.s data from the $\mathrm{CMM}$, we can produce charts such as Figure 6 which shows the thickness variation throughout the entire run for cable SSC12-00005. Similar charts can be produced for keystone angle and cable width. Table 3 lists the statistics gathered by the CMM during the nun. 
SSC * 12-0000s In-line Cable Data (Table 3)

\begin{tabular}{|c|c|c|c|c|}
\hline & PSI & Angle & Width & Thickness \\
\hline Average & 2547.04132 & 1.60452 & 0.36651 & 0.05741 \\
\hline Minimum & 2442.00000 & 0.00200 & 0.36596 & 0.05727 \\
\hline Maximum & 2467.00000 & 1.62700 & 0.36709 & 0.05763 \\
\hline Standad/Der & 2.91589 & 0.08448 & 0.00009 & 0.00006 \\
\hline
\end{tabular}

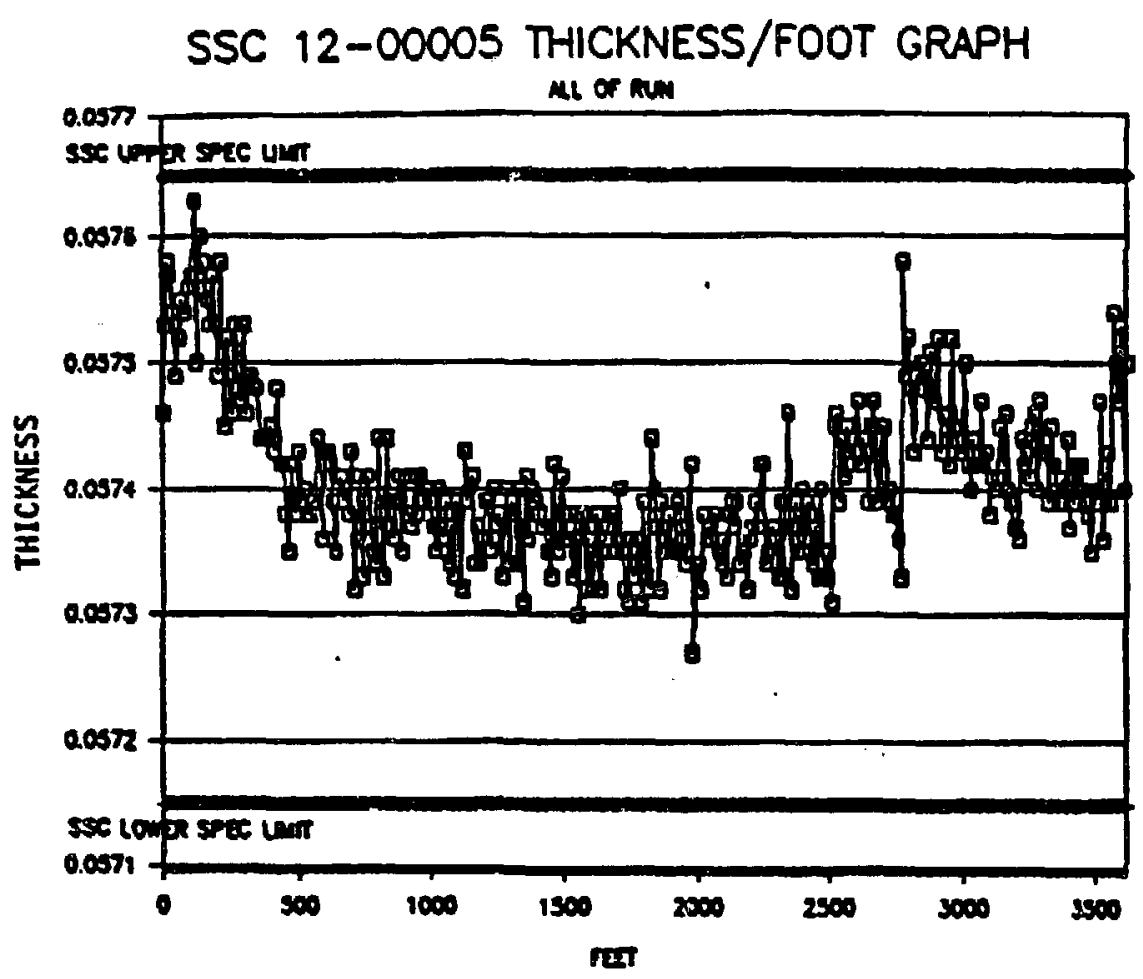

Figure 6

SSC R\&D Cable (Table 4)

\begin{tabular}{|c|c|c|c|c|c|}
\hline Cable & Type & Leirgth & Is & Fl. Dia. & Notes \\
\hline SSCIGC14RD & 1.8 Outer & 8495 & NA & Gum & $14^{-}$dia billet \\
\hline SSC12-00003 & 15 Inner & 1562 & $7464(7 \mathrm{~T})$ & 9um & Unannealed NbTi \\
\hline SSC12-00004 & 1.5 Inner & 2054 & $6950(7 T)$ & $6 u m$ & Unannealed NoTi \\
\hline SSC13-00001 & 1.5 Inner & 2750 & $7968(7 \mathrm{~T})$ & 9um & 0.45 LAR \\
\hline SSC14-00003 & 1.5 Inner & 1821 & $7464(7 \mathrm{~T})$ & 6um & Annealed NbTi \\
\hline
\end{tabular}

SSC R\&D CABLE

Table 4 lists some of the R\&D cable manufactured during 1989 and 1990 to date. Of considerable interest is SSC-IGC14RD. This cable is SSC outer type material incorporating strand from a $14^{\prime \prime}$ diameter single stack extrusion billet. This is a scale-up from the standard 12" diameter extrusion billet, and in design will improve yields and lessen fabrication costs. 
Problems involving the diffusion barrier and Cu/sc ratio led to less than optimum associated properies. This first attempt at a $14^{n}$ billet yielded lo, is piece. lengthis and overall yield, as well as bend test failures. It is generally believed thas the reasons for this poor strand performance are known and there is confidence that future $14^{\prime \prime}$ billets will behave much better. Somewhat s.pprising, the cable le measurements showad less than $2 \%$ degendation with cabling.

The other R\&D cables listed in Table 4 are al SSC inner type with various parameters differentiating them from production material. Cables SSC12-00003, 12-00004, and 1400003 are comprised of strand with different filament diameter and/or different NbTi raw material history. Cable SSC13-00001 was fabricated from wire with closely spaced 9um diameter filaments. Table 4 lists the basic characteristics of these R\&D cables and the length of each nun.

\section{SUMMMRY}

Of the total cable made during 1989 and early 1990, 76,256 feet was SSC production outer cable, 52,250 feet was SSC production inner, 8495 feet was R\&D outer, and 8187 feet was R\&D inner cable. In most cases the electrical values of the wire and cable fell amply above the SSC requirements. The piece lengths and yields of many of the billets. however, do not meet the present goals of the SSC project. These shortcomings are being addressed in the present manufacturing scalc-up program. Cable degradation numbers have been relatively low, and increased understanding of the degradation parameters can lead to degradaions consistently under $4 \%$ or better.

Throughout the past year a considerable amount has been leamed about the cabling process and an initial foundation has been set for future programs, specifically the newly proposed SOmm SSC Dipole Program. The experience and knowledge developed in the alowm magnet program will help promote a successful transition to a new cable design if required

\section{REFERENCES}

1. M.J. Baggeth, R. Leedy, C Salumarsh, and J.C. Thompling, The Magnet Component Daubase System", paper UI-B-3, IISSC, Miami Beach, FL, March I4-16, $19 \%$.

2. M. Garber and W.B. Sampson, "Quality Control Testing of Cables for Accelerator Magneta", ISSC, New Orieans, LA, Feb. 8-10, 1989.

3. SSC Specification SSC-MAG-M-4142, NbTi Superconductor Cable for SSC Dipole Magnets.

4. A.F. Greene and R.M. Scanlan, "Elements of a Specification for Superconducting Cable and Why They Are Important for Magnet Construction", ISSC, New Otieans. LA, Feb. 8-10, 1989.

\section{DISCLAIMER}

This report was prepared as an account of work sponsored by an agency of the United States Government. Neither the United States Government nor any agency thereof, nor any of their employees, makes any warranty, express or implied, or assumes any legal liability or responsibility for the accuracy, completeness, or usefulness of any information, apparatus, product, or process disclosed, or represents that its use would not infringe privately owned rights. Reference herein to any specific commercial product, process, or service by trade name, trademark, manufacturer, or otherwise does not necessarily constitute or imply its endorsement, recommendation, or favoring by the United States Government or any agency thereof. The views and opinions of authors expressed herein do not necessarily state or reflect those of the United States Government or any agency thereof. 